\title{
A RESPOSTA DAS POLITÉCNICAS FINLANDESAS AOS DESAFIOS DAS POLÍTICAS DE INOVACÃO E DE DESENVOLVIMENTO REGIONẢL
}

\author{
Anu Lyytinen* \\ Seppo Hölttä ${ }^{* *}$
}

\begin{abstract}
Este trabalho apresenta uma análise do desenvolvimento recente de uma parte do ensino superior na Finlândia. Seu objetivo é analisar como as politécnicas finlandesas reagiram às novas exigências para que se tornassem responsivas às necessidades regionais e como elas construíram as competências necessárias para esse engajamento regional. O quadro de referência teórica central são os elementos de mudança institucional descritos por Burton Clark (1998) em sua análise sobre as universidades empreendedoras. Em particular, o artigo focaliza os canais e interfaces que essas instituições estabeleceram com outros atores no âmbito regional.

Palavras Chaves: Finlândia, ensino superior, desenvolvimento regional, Politécnicas, empreendedorismo acadêmico.
\end{abstract}

\section{INTRODUÇÃO}

Um dos desafios atuais enfrentados pelas políticas de educação superior em muitos países europeus é o de integrar mais claramente as instituições de educação superior ao desenvolvimento social e econômico da sociedade (Hölttä, 1995, p.15; Maassen 2000, p.377). A globalização da economia - apoiada pela liberalização do comércio, a desregulamentação dos mercados, o aumento da concorrência global do comércio internacional e o desenvolvimento de tecnologias de informação constitui a principal razão que levou os formuladores de políticas nessa área a propor a necessidade do fortalecimento inovação baseada na tecnologia. Em muitos países ocidentais, essa perspectiva implica conceber o sistema de ciência e tecnologia como o principal elemento do desenvolvimento da sociedade (Castells 2000; Nieminen

\footnotetext{
* Doutora e pesquisadora sobre Ensino Superior da Universidade de Tampere, Finlândia (HEG)

Departamento de Gestão de Estudos, FIN-33 014 Universidade de Tampere. anu.lyytinen@uta.fi

** Professor Titular da Universidade de Tampere, Finlândia. seppo.holtta@uta.fi
}

2005, p.13-14; OECD, 1999, p.38; Schienstock, 1999, p.48; Slaughter; Leslie, 1997, p.25).

A reforma do ensino tecnológico na Finlândia, que deu origem ao sistema politécnico, data do final dos anos 90. Essa iniciativa integrava um conjunto de mudanças mais amplo na estratégia político-administrativa do país. A instituição do sistema politécnico foi a maior reforma do sistema de educação do país na década de noventa (Raivola et al. 2001). As politécnicas - ou Universidades de Ciências Aplicadas, ou ainda o sistema de ensino profissional superior (AMK), ${ }^{1}$ conforme são

${ }^{1} \mathrm{Na}$ Finlândia, assim como na Alemanha, Holanda e nos demais países nórdicos, o sistema de ensino superior é binário, isto é, ele é oferecido em duas modalidades de instituições: as universidades e as politécnicas. As politécnicas (ou universidade de ciências aplicadas - AMK, sigla para ammattikorkeakoulu, em finlandês) são instituições voltadas para a oferta de formação e certificação para o trabalho, aquilo que no Brasil chamaríamos de cursos tecnológicos - cursos voltados para o desenvolvimento de perfis de competências buscados pelas empresas, que a literatura internacional também denomina como "formação vocacional". Já as universidades oferecem programas de cunho mais acadêmico, que dão acesso ao diploma de bacharel. Em 2010, ao todo, 66\% dos jovens que ingressaram no ensino superior naquele país o fizeram no sistema de politécnicas, e 34\% se matricularam nas universidades. Dados sobre as politécnicas Finlandesas (em inglês) encontram-se em www.stat.fi/ til/akop/index en.html e sobre as universidades em www.stat.fi/til/yop/index_en.html. (Nota da tradução). 
conhecidas na Finlândia - organizaram-se paralelamente ao setor universitário para dar conta da formação aplicada e vocacional de nível superior, intimamente ligada às necessidades da indústria, dos negócios e das profissões. Isso significa que, desde então, o sistema de educação superior finlandês se diferenciou em dois tipos de instituições: as universidades e as politécnicas. Atualmente, a educação superior da Finlândia engloba 16 universidades e 25 politécnicas. Esse tipo de sistema público, formado por instituições universitárias e não-universitárias, financiado basicamente pelo governo nacional, é comum em várias partes do mundo (Clark, 1983, p.54, 102). Entretanto, o que torna a experiência finlandesa excepcional do ponto de vista da experiência internacional é o fato de que as politécnicas sejam financiadas tanto pelo governo central como também pelas autoridades locais (Kohtamäki, 2004, p.49).

O sistema politécnico foi criado pela fusão de 210 instituições vocacionais de nível pós-secundário e de nível superior em 29 politécnicas. As principais razões que motivaram a reforma estão relacionadas a algumas dificuldades funcionais então detectadas no sistema educacional finlandês, às mudanças previsíveis (e já então perceptíveis) no mercado de trabalho, assim como à influência de experiências internacionais. A reforma tinha por objetivo melhorar a eficácia do sistema educacional, visando particularmente a tornar a educação vocacional mais flexível, funcional e atraente, capaz de responder às mudanças no mercado e no ambiente de trabalho. Seus objetivos concretos eram elevar a qualidade da educação, aumentar sua compatibilidade e comparabilidade com experiências internacionais, torná-la mais receptiva às mudanças no mercado de trabalho e acompanhar as mudanças na dinâmica do desenvolvimento regional do país (Lei nº206/2002; Salminen, 1995, p.319; Salminen 1997, p.312-325).

Um ponto central nessas reformas foi dotar as politécnicas de uma relevância regional mais nítida - em função de suas responsabilidades na educação, pesquisa e desenvolvimento tecnológico - mediante a oferta de uma infraestrutura de apoio ao trabalho e à qualidade de vida em cada região. A finalidade principal era aprimorar as alternativas de formação profissional nas regiões que não possuíssem sua própria universidade multidisciplinar. Esperava-se que as politécnicas contribuíssem para o desenvolvimento regional de acordo com seu perfil específico de competências. Essa contribuição se daria através da provisão de uma educação multifacetada, capaz de formar uma força de trabalho de alto nível, e pela participação dessas instituições na criação de processos sustentáveis de inovação no nível regional (Lei ${ }^{\circ}{ }^{3} 19 / 1994$; Lei $\left.n^{0} 206 / 2002\right)$.

A reforma legislativa de 2003 ampliou as opções de funcionamento das politécnicas e as suas responsabilidades regionais. A nova Lei das Politécnicas (nº351/2003) ampliou seus objetivos, colocando as atividades de pesquisa aplicada e de desenvolvimento tecnológico no mesmo patamar das atividades de ensino. A reforma também fortaleceu as responsabilidades regionais das politécnicas, enfatizando a necessidade de se alinhar o ensino, a pesquisa aplicada e o desenvolvimento tecnológico às necessidades do trabalho e do desenvolvimento regional. Segundo a Lei, "a função das politécnicas é oferecer um ensino que atenda às demandas do trabalho, baseado na atividade de pesquisa e de desenvolvimento tecnológico e artístico e que leve à formação de especialistas". Ademais, as politécnicas ficaram responsáveis por "desenvolver atividades de pesquisa aplicada e desenvolvimento tecnológico, considerando o perfil industrial de cada região, de forma a dar embasamento para as atividades de ensino e apoiar o desenvolvimento da região e de seu mercado de trabalho". Ao mesmo tempo, a Lei afirmou a autonomia dessas instituições para decidir sobre questões internas. O objetivo central do fortalecimento da autonomia foi abrir alternativas para a cooperação flexível e rápida com o comércio, indústria e serviços de cada região (Lei n ${ }^{\circ} 206 / 2002$ ). Dessa maneira, a interpretação dos objetivos e a definição de metas e de estratégias para sua implementação permanecem sob o controle de cada politécnica e devem ser negociados entre essas 
instituições e outros atores relevantes no nível regional. É evidente que o crescimento das responsabilidades regionais e o fortalecimento dos canais de interação com outros atores criaram desafios para que as politécnicas desenvolvessem uma postura mais empreendedora (cf. Auvinen, 2004, p.158; Clark, 1998).

Este artigo baseia-se na tese de doutorado de um dos autores (Lyytinen, 2011). Seu objetivo é analisar como as politécnicas finlandesas reagiram às novas exigências para que se tornassem responsivas às necessidades regionais e como elas construíram as competências necessárias para esse engajamento regional. O quadro de referência teórica central são os elementos de mudança institucional descritos por Burton Clark (1998) em sua análise sobre as universidades empreendedoras. Em particular, o artigo focaliza os canais e interfaces que essas instituições estabeleceram com outros atores no âmbito regional.

\section{ELEMENTOSDEMUDANÇA ORGANIZACIONAL ASSOCIADOS À EMERGÊNCIA DA UNIVERSI- DADEEMPREENDEDORA}

Um dos principais objetivos das pesquisas sobre políticas de inovação, desde 1990, está em entender e explicar como as instituições de ensino superior e a própria ciência mudam como parte do processo de construção da sociedade do conhecimento (Miettinen; Tuunainen 2006, p.16). Modelos conceituais, como as relações de hélice tripla entre universidades, indústria e governo (Etzkowitz; Leydesdorff, 1997), a universidade empreendedora e a universidade-empresa (Clark, 1998; Etzkowitz et al 2000; Marginson; Considine, 2000), o capitalismo acadêmico (Slaughter; Leslie, 1997) e a mudança do Modo 1 ao Modo 2 da produção de conhecimento (Gibbons et al. 1994; Nowotny; Scott; Gibbons, 2002) são tentativas relevantes para redefinir o papel social da universidade e da ciência na sociedade de conhecimento (Miettinen; Tuunainen, 2006, p.16). Cada um desses modelos enfatiza mudanças em diferentes ní- veis: da convergência entre modelos institucionais das universidades, indústria e governo às mudanças na organização, no trabalho acadêmico e no processo de produção de conhecimento. Um ponto essencial em todos esses modelos é questão sobre como a ciência e as instituições de ensino superior contribuem ativamente para a sociedade do conhecimento.

Desde o final dos anos 1990, o conceito de empreendedorismo, como característica de algumas instituições de ensino superior e de acadêmicos individualmente, passou a receber uma crescente atenção da literatura sobre ensino superior e ciência (Kristensen, 1999, p.35-36; Miettinen; Tuunainen, 2006, p.16). Esse conceito vem sendo aplicado às instituições de ensino superior que reconheceram ativamente, como parte de seus objetivos, a terceira missão definida por Etzkowitz e Leydesdorff (1997), isto é, seu engajamento consciente no desenvolvimento econômico e social, ao lado das tarefas tradicionais de educação e pesquisa. $\mathrm{O}$ comportamento empreendedor é visto como uma resposta das instituições de ensino superior e dos próprios acadêmicos frente aos desafios colocados por um ambiente em rápida transformação, em particular, como alternativa para fazer frente à escassez financeira e às pressões políticas (Clark, 1998; Gibbons et al. 1994; Etzkowitz et al. 2000, p.313330; Etzkowitz; Klofsten, 2005, p.246-247; Jacob et al, 2003, p.1555-1556; Marginson; Considine, 2000; Miettinen et al, 2006, p.16; Nowotny; Scott; Gibbons, 2002; Slaughter; Leslie, 1997).

A definição de empreendedorismo, nessa literatura, enfatiza a noção de que ele não é somente um fenômeno individual e extemporâneo, mas tambémé social e organizado (Jacob et al, 2003, p.1556). Do ponto de vista institucional, o conceito de empreendedorismo remete às universidades como organizações empreendedoras (Williams, 2003, p.10). A questão é, portanto, basicamente sobre governança, gestão e liderança dessas organizações. A governança é um conceito relacionado à missão e ao propósito da organização, seus sistemas de tomada de decisões e de alocação de recursos, seu padrões de distribuição de autoridade, assim como 
às relações que se estabelecem entre a instituição e o ambiente externo (Marginson; Considine, 2000, p.7). Assim sendo, o conceito de governança está ligado às estruturas e aos processos pelos quais os atores institucionais interagem e influenciam uns aos outros e se comunicam com atores relevantes do ambiente externo (Birnbaum, 1991, p.4).

O estudo de Burton Clark (1998) intitulado Creating Entrepreneurial Universities: Organizational Pathways of Transformation [A Criação das Universidades Empreendedoras:Caminhos Organizacionais de Transformação] pode ser considerado o estudo pioneiro sobre o advento e características da universidade empreendedora. Desde então, o número de trabalhos nesse campo aumentou, e os conceitos de universidade-empresa e de universidade empreendedora vêm sendo empregados em diferentes estudos relativos à mudança organizacional e ao trabalho acadêmico em universidades (e.g. Etzkowitz et al. 2000; Marginson; Considine, 2000). Em seu estudo, Clark (1998) buscou compreender os caminhos de mudança institucional experimentado por algumas universidades que levaram ao desenvolvimento de um comportamento empreendedor. Sua pesquisa está centrada na realização de cinco estudos de caso, cada qual focado em uma universidade europeia (inglesas, escocesas, suecas e finlandesas). A suposição básica desse trabalho é a de que o empreendedorismo surge como resposta a situações onde há um crescente desequilíbrio entre as demandas do meio e a capacidade de resposta das instituições. Dessa situação, nasce a necessidade de transformar os elementos organizacionais dessas instituições para fortalecer sua capacidade de reagir de forma mais flexível e seletiva às mudanças que acontecem tanto no meio externo como também internamente, nas diferentes áreas de conhecimento. (Clark, 1998; veja também Sporn, 1999, p.60). Como resultado da análise dos casos estudados, Clark aponta cinco elementos de mudança organizacional como os mais relevantes para se entenderem as transformações que dão origem às universidades empreendedoras. Esses elementos de mudança organizacional são os seguintes: o fortalecimento do núcleo central de direção, o desenvolvimento de uma periferia institucional expandida, a diversificação dos fundos de custeio da universidade, o estímulo do núcleo acadêmico tradicional e o desenvolvimento de uma cultura empreendedora integrada (Clark, 1998.) Portanto, sua análise articulou processos de gestão e governança com as funções acadêmicas tradicionais das universidades. Ao invés de enfatizar somente o aspecto gerencial do processo de mudança nas universidades, Clark sublinha a importância de processos que permitam a mescla de novos objetivos e comportamentos com valores acadêmicos tradicionais, permitindo a integração e a mudança nas duas culturas (veja também Hakala et al. 2003, p.17).

Segundo Clark, o "fortalecimento do núcleo central de direção" refere-se aos esforços da instituição de ensino superior para fortalecer e sistematizar sua capacidade gerencial. Esse processo pode ser produzido de diversas formas, pode ser centralizado ou descentralizado, porém é essencial que ele se produza pela mobilização de um núcleo administrativo e também de grupos acadêmicos, de forma a conciliar os novos valores gerenciais com os valores acadêmicos tradicionais (Clark, 1998, p.5-6).

As universidades empreendedoras também criam unidades, centros e programas que ultrapassam as suas fronteiras tradicionais, criando vínculos ativos com grupos, interesses e organizações do seu entorno institucional. Essas novas unidades correspondem ao que Clark chamou de periferia institucional expandida. Tipicamente, essas unidades promovem novas competências e geram renda, o que ajuda as instituições de ensino superior a diversificarem suas bases de custeio. Por sua vez, uma base de custeio diversificada amplia a capacidade de autorregulação dessas instituições e abre a possibilidade de mudança. Clark enfatiza especialmente as fontes de financiamento de segunda e terceira ordem ${ }^{2}$, referindo-se a uma diver-

${ }^{2} \mathrm{Na}$ literatura internacional sobre financiamento do ensino superior, recursos de segunda ordem são aqueles obtidos através do financiamento de projetos de pesquisa junto a fundações e agências de fomento à pesquisa (públicas ou privadas). Recursos de terceira ordem são os recursos obtidos junto a empresas, governos locais, grupos filantrópicos, etc, como pagamento a serviços prestados pela universidade. Para Clark (1998, p.6), essa última fonte de recursos é especialmente importante já 
sificação de recursos provenientes de diversas fontes externas. Quando uma instituição de ensino superior fortalece o seu núcleo decisório, expande sua periferia institucional e diversifica suas fontes de recursos, a área acadêmica central pode, muitas vezes, permanecer ligada a departamentos organizados em torno de disciplinas específicas e em programas de ensino tradicionais (Clark, 1998, p.7). Para sustentar a mudança, uma questão essencial é como estimular a área acadêmica central, de forma a que ela também seja levada a interagir com o ambiente externo à instituição mediante o desenvolvimento de programas inovadores tanto de ensino como de pesquisa, crie novos vínculos e explore oportunidades de financiamento de terceira ordem. Para dar conta desse processo integrativo, Clark usa o conceito de uma cultura empreendedora integrada: universidades empreendedoras também se caracterizam pelo desenvolvimento de uma cultura profissional que assume e busca a mudança (1998, p.3-8).

Mesmo que Clark não tenha incluído o compromisso regional como uma dos elementos de mudança institucional, em todos os casos que ele estudou é possível observar que a realização do potencial de mudança social da universidade acompanhou o desenvolvimento de novos canais de comunicação com a sociedade local, o que constitui um fator significativo para explicar a sua transformação em instituições responsivas e empreendedoras (veja OECD, 1999, p.41).

\section{DADOSE MÉTODO}

O estudo de doutorado no qual este artigo se baseia empregou o desenho de múltiplos estudos de caso (Lyytinen, 2011). A pesquisa concentrou-se na análise da experiência de quatro politécnicas (aqui denominadas caso A, caso B, caso $\mathrm{C}$ e caso D). Todas elas se caracterizavam por serem instituições de ensino superior de tamanho

que ela se constitui num montante extra que pode ser usado pela universidade para custear reformas (de infraestrutura e também institucionais) necessárias para dar dinamismo à universidade (Nota da Tradução). médio, multidisciplinares e regionais. Além disso, todas elas haviam sido reconhecidas na mesma época e vinham funcionando como politécnicas pelo mesmo período de tempo. Ademais, a boa avaliação alcançada pelas politécnicas dos casos A, B e Cna avaliação externa realizada no âmbito do Programa Centro de Excelência para o Impacto no Desenvolvimento Regional, a cargo do Conselho Finlandês de Avaliação do Ensino Superior, também é um indicativo da disposição e ativo engajamento dessas instituições no sentido de se tornarem responsivas do ponto de vista do desenvolvimento regional.

Nesse estudo, as politécnicas escolhidas estão enquadradas pelas particularidades que caracterizam seus ambientes locais e regionais. Assim, uma justificativa importante para a escolha dos casos decorre do fato de que, embora todas elas fossem instituições de ensino superior de tamanho médio, multidisciplinares e regionais, cada uma delas está inserida em um ambiente de inovação regional diferente. Isso significa que seu estudo produz perspectivas contrastantes e complementares sobre a questão central desta pesquisa. O estudo concentrou-se na investigação do papel das politécnicas em dois tipos de ambientes regionais de inovação: regiões que contam com politécnicas, universidades e institutos de pesquisa e regiões com uma politécnica e um consórcio de universidades, porém sem sua própria universidade. Os dados da pesquisa foram coletados mediante a aplicação de técnicas de análise de stakeholders ${ }^{3}$ e a realização de entrevistas temáticas. O roteiro das entrevistas considerou informações constantes em documentos e relatórios oficiais para cada caso. Essa documentação serviu de base para as entrevistas. O quadro de referência teórico do

${ }^{3}$ Para cada caso analisado, foi realizado um exercício de análise de stakeholders, para o qual foram convidados atores com responsabilidade formal na política de desenvolvimento da região onde estava situada a Politécnica. Assim, os convites para o exercício incluíram o Reitor da Politécnica, o Diretor de Desenvolvimento Empresarial da cidade, o Diretor de Desenvolvimento Regional do Conselho Regional, o Diretor Administrativo do Centro Regional de Tecnologia, o Diretor executivo da Unidade de Emprego e o Oficial de Ligação ou equivalente da Universidade ou Consórcio de Universidades presente na região. 
estudo são os elementos de mudança organizacional analisados por Burton Clark (1998) para compreender a gênese de universidades empreendedoras. O estudo explora a percepção da alta liderança acadêmica e administrativa ${ }^{4}$ das politécnicas sobre como essas instituições se capacitaram para um maior engajamento no desenvolvimento regional. Assim, o estudo explora como, na visão desses atores estratégicos, essas instituições fortaleceram sua gestão interna, constituíram canais de interação com outros atores externos, diversificaram suas fontes de financiamento, estimularam o núcleo acadêmico central e construíram uma cultura empreendedora integrada, mesclando os novos valores de gestão empreendedora com a cultura acadêmica tradicional (Clark, 1998).

Este artigo analisa como, em cada um dos casos estudados, as politécnicas se qualificaram para assumir compromissos com o desenvolvimento regional, e, em particular descreve o tipo de relações e interfaces essas instituições construíram para se relacionar com outros atores regionais. A análise se desdobra em duas etapas: a primeira tem como foco as mudanças ocorridas caso a caso, e a segunda faz uma comparação entre os quatro casos analisados.

\section{A RESPOSTA DAS POLITÉCNICAS AO DESA- FIO REGIONAL}

\section{Análise dos casos}

Todas as politécnicas estudadas obtiveram licenças permanentes de operação entre 1996 e em 1997. O caso A se formou a partir da consolidação de dez instituições, parte delas originalmente instituições de ensino pós-secundário e outra parte de ensino tecnológico superior. Essas instituições se localizavam em seis municípios situados em diferentes partes da Ostrobothnia do Sul, uma

${ }^{4} \mathrm{O}$ texto original faz menção apenas às lideranças administrativas, entretanto, o estudo incluiu, além da alta administração executiva, os reitores e diretores de unidades das Politécnicas. Na tradição brasileira esses últimos são considerados como parte da liderança acadêmica da instituição. (Nota da Tradução, após consulta aos autores). província situada na parte ocidental da Finlândia, com aproximadamente 194.000 habitantes. A mantenedora da politécnica do caso A, e titular da licença de seu funcionamento, é a Autoridade Municipal Conjunta para Educação de Seinäjoki, que pertence a 14 municípios (Conselho Nacional de Educação, 2003; Riukulehto, 2007, p.72-76). Essa politécnica oferece ensino em sete campos de educação. Ela própria definiu seu perfil como o de uma instituição regional de ensino superior que oferece ensino e serviços numa área geográfica dispersa, atendendo a diferentes partes da província. Os contatos dessa instituição com outras organizações regionais assumem diferentes formatos.

O ambiente regional de inovação da Ostrobothnia do Sul apresentou desafios particulares até o início dos anos de 1990, devido à baixa presença de instituições de ensino superior e de pesquisa. De acordo com os depoimentos dados por SA $11^{5}$ e SA14, essa politécnica desempenhou um papel relevante nos processos de reforma e construção do sistema regional de inovação. A politécnica tem duas unidades de extensão e desenvolvimento - o Centro de Pesquisa em Serviços Sociais e de Saúde e o Centro-SC, especializado em pesquisa aplicada e serviços de consultoria voltados para a indústria regional. Ela também desenvolveu inúmeros canais de contato com outras organizações regionais e oferece sua experiência através de programas extensão em diferentes partes da região. A Politécnica é vista como “a investidora estratégica que sempre toma a iniciativa para alugar ou financiar a construção de novas instalações" (veja também Riukulehto 2007, p.139). Essas realizações foram muito importantes para a região, já que ali as instituições e organizações do ambiente regional de inovação só se fortaleceram a partir do final da década de noventa.

A politécnica Caso B está localizada em Satakunta, uma província com aproximadamente 230.000 habitantes no sudoeste da Finlândia. Essa

${ }^{5}$ Os códigos IA a I10 se referem às entrevistas realizadas junto às lideranças de cada instituição estudada. Os códigos SA1 a SA15 se referem aos depoimentos coletados nos exercícios de análise de "stakeholders" conduzidos contando com a presença de autoridades institucionais e regionais para cada uma das instituições estudadas. 
Politécnica foi formada a partir da fusão de 13 instituições municipais de educação. Atualmente, ela engloba três faculdades que oferecem ensino e atividades culturais em cinco áreas: tecnologia, comunicação e transporte, negócios e administração, serviços sociais e saúde. Suas atividades estão espalhadas por cinco municípios (Conselho Nacional de Educação, 2003). A missão que orientou a fundação dessa politécnica foi a de atender às necessidades da região (Jaatinen, 1999). Por isso, desde o início, suas atividades se estruturaram em função das demandas regionais. Em 1997 foi fundado o Instituto O'Sata de Pesquisa e Desenvolvimento como uma unidade de extensão que oferecia serviços de pesquisa e desenvolvimento sob contrato com o setor empresarial. O Instituto tambémé reconhecido como uma importante instituição de intermediação no processo de transferência de conhecimento e de competências para as empresas regionais (I8, SA9).

Os principais desafios do ambiente de Satakunta são a heterogeneidade do setor empresarial e o baixo desenvolvimento das empresas na região. Em particular, há poucas empresas de médio e grande porte. Além disso, a tradição de empreendedorismo é relativamente limitada na região como um todo. O número de empreendedores tem inclusive diminuído no período mais recente (I8; I9; Porin korkeakoululaitoksen yhteistyöstrategia, 2002, p.3). Como resposta a essa situação, a politécnica do caso B adotou um programa de Aceleração de Empresas ${ }^{6}$ como parte do O’Sata (I9; SA8), voltado para promover o empreendedorismo na região. Essa Politécnica tam-

${ }^{6}$ O Acelerador de Empresas consiste numa solução pedagógica voltada para estabelecer pontes entre o ensino e o ambiente empresarial, estimulando atividades de ensino, pesquisa e extensão voltadas para o mundo do trabalho e das empresas e dando ênfase especial na formação de competências necessárias para o empreendedorismo. Suas atividades estão fortemente conectadas com todas as áreas de ensino através da oferta de estágios em projetos desenvolvidos em conjunto com empresas. Projetos e propostas de novos negócios nascidos dessa interação dos alunos com as empresas são avaliados e desenvolvidos sob orientação dos professores. Os objetivos do programa são, de um lado, estimular um empreendedorismo intensivo em conhecimento entre os alunos, e, de outro, adensar a rede de relações entre a Politécnica e as empresas da região (Nota da Tradução, após consulta aos autores). bém desenvolveu o Instituto de Automação dentro do O’Sata, que tem por objetivo criar relações duradouras com as empresas parceiras e ampliar a oferta de recursos humanos especializados em automação na região. A tarefa de familiarizar as empresas locais com os recursos e as competências englobadas pelo Instituto de Automação constituiu um desafio bem sucedido para essa Politécnica (Marttila et al. 2004, p.92). O Instituto também conseguiu mobilizar fundos de várias fontes de terceira ordem, tais como as autoridades municipais e empresas, e conta com o apoio da União Europeia, através do Programa "Centros de Especialização" (SA7; SA8; SA9, veja também Tulkki; Lyytinen, 2001, p.62-63).

A politécnica caso C está localizada na Finlândia Central, região que conta com uma população de aproximadamente 268000 habitantes. Diferente dos outros casos, essa politécnica é privada. Otitular de sua licença é a Jyväskylä Polytechnic $L t d$. A empresa é de propriedade conjunta da Cidade de Jyväskylä (sócia majoritária) e de três outras Autoridades Municipais Conjuntas de Educação da região. Após sua fundação, essa Politécnica experimentou uma expansão marcada por sucessivas extensões da sua licença de operação, na medida em que novas instituições foram sendo agregadas (Suosara, 2007, p.132). As expectativas das autoridades provinciais estão descritas na definição de sua missão. Nela está estabelecido que a Politécnica deve cooperar para aumentar o bem estar da região da Finlândia Central, mediante a promoção de competências especializadas, a consolidação de redes e a internacionalização do ambiente de trabalho através da oferta de ensino, pesquisa e extensão de qualidade e voltado para as necessidades do futuro da região".

No caso dessa Politécnica, a expansão da periferia institucional foi alcançada mediante a exposição das suas escolas ao ambiente externo, ao invés da criação de unidades de extensão independentes, como se viu nas experiências anteriores. De acordo com entrevistados ligados a essa

${ }^{7}$ No original: Centre of Expertise www.oske.net/en (Nota da Tradução). 
instituição (SA4, SA5 e SA6), as relações entre a politécnica e o ambiente externo assumem a forma diversos acordos de cooperação com companhias e organizações públicas, de desenvolvimento de projetos, de centro de especialização e do desenvolvimento de programas de educação para o empreendedorismo.

A politécnica caso $C$ está localizada em um ambiente desafiador devido à polarização da região: conforme o entrevistado I3 argumentou, a região de Jyväskylä é desenvolvida e está crescendo, porém, ao seu redor, existem grandes áreas periféricas onde ainda se faz necessário um trabalho voltado para o desenvolvimento regional. A cidade de Jyväskylä apresenta um ambiente rico, marcado pela presença de várias instituições de ensino superior: a universidade, a politécnica, um centro de pesquisa técnica, e várias instituições de ensino profissional. Isso significa que, nesse ambiente, a politécnica $\mathrm{C}$ é uma dentre várias concorrentes que busca os mesmos clientes e parceiros de cooperação (cf. Thompson, 2003, p.27; cf. também Lyytinen; Marttila, 2009, p.36-37; Marttila et al. 2004, p.107-108). Fora da região de Jyväskylä, nas áreas periféricas, a estrutura empresarial é diversa e as organizações municipais e o setor público estão enfraquecidos. A Politécnica também não oferece serviços nessas regiões. De acordo com os entrevistados SA4 e SA6, o desafio estratégico é,
Estatísticas da Finlândia, 2008).

A politécnica D cresceu nas áreas de educação tecnológica e econômica, tendo como base a fusão da experiência do antigo Instituto Técnico com a do Instituto Florestal e a do Instituto de Artes e Comunicação. Por esse motivo, a instituição se desenvolveu em áreas tecnológicas voltadas para atender à demanda do setor empresarial, oferecendo cursos profissionais em áreas tecnológicas, de administração de empresas, cultura e gerenciamento de recursos naturais. Essas carreiras refletem a especialização econômica e industrial da região. A atividade industrial em Tampere é famosa pela especialização nas áreas de automação de máquinas, eletroeletrônica e mídia. A Politécnica D tem uma longa tradição na oferta de ensino tecnológico (Conselho Nacional de Educação, 2003, p.139; SA2). Segundo o depoimento de SA2, a reforma das atividades de extensão e o estabelecimento de laços de cooperação com o setor empresarial teve início com os trabalhos de final de curso dos estudantes, em particular aqueles ligados à área de engenharia. A principal meta dessa Politécnica ainda é estimular o núcleo acadêmico da instituição através da integração das atividades de extensão e cooperação com o currículo dos cursos, em particular sob a forma de projetos, trabalhos de final de curso e estágios compulsórios (I2). No presente, todas as escolas que compõem a politécnica já estabeleceram relações com empresas da região, porém o empreendedorismo ainda não está disseminado de forma uniforme em todas as áreas. Semelhante à região de Jyväskylä, o ambiente na região de Tampere também é desafiador devido à coexistência de outras instituições de ensino superior e institutos de pesquisa (cf. também Marttila et al. 2004, p.107-108).

\section{Análise comparada dos casos}

Os resultados indicam que as relações e interfaces das politécnicas com outros atores adotaram formas e propósitos diferentes em cada caso. As Politécnicas estabeleceram unidades separadas 
para agir como intermediárias na disseminação de conhecimentos e prestação de serviços. Criaram Aceleradores de Empresas e promoveram a educação empresarial com o objetivo de expandir o empreendedorismo nas regiões. Da mesma forma, elas estabeleceram acordos de parceria, criando ambientes de pesquisa cooperativa com empresas. Por outro lado, as Politécnicas criaram canais de comunicação mediante o seu envolvimento em conselhos regionais, grupos de trabalho e redes. Esses canais permitem transmitir informações sobre a politécnica para grupos externos e, ao mesmo tempo, coletar informações sobre o ambiente, que podem ser usadas para o desenvolvimento de suas atividades. Nos casos das Politécnicas A e B, o compromisso regional parece ser uma escolha deliberada, com a oferta de ensino e pesquisa e busca de parcerias em diferentes distritos de suas respectivas províncias. Nos casos das Politécnicas $\mathrm{C} \mathrm{eD}$, o perfil regional - no sentido descrito acima - não é tão explícito.

Ao contrário do que foi observado em vários estudos internacionais (como, por exemplo, o de Slaughter ; Leslie 1997), este estudo mostra que a necessidade de garantir recursos ou obter financiamento externo foi muito raramente mencionada como a principal razão para o desenvolvimento da periferia institucional expandida, com a criação de unidades especiais ou o desenvolvimento de e estratégias de cooperação com atores externos. Ao contrário, o objetivo dessas iniciativas foi o de estimular as atividades acadêmicas, trocar, fornecer e obter informações do meio, mediar processos de transferência do conhecimento e, assim, gerar prestígio para a instituição. Entretanto, esse processo também garantiu acesso a recursos externos, mediante contratos de pesquisa e de ensino corporativo e o acesso a recursos da União Europeia assim como a outras fontes de apoio públicas (Conselho Nacional de Educação, 2008; cf. Clark, 1998, p.6, 45). A parcela de recursos de segunda e terceira ordem, no caso das politécnicas estudadas, variou de 9\% a 24\% entre os anos de 2004 a 2006. Entretanto, os recursos de terceira ordem raramente geraram renda expressiva e são vinculados a pro- dutos predefinidos e a necessidades específicas do cliente. Por outro lado, em comparação com as universidades, a fatia de recursos de segunda ordem canalizada por intermédio de Conselhos de Apoio à Pesquisa ainda tem um papel secundário no caso das politécnicas. Ademais, as essas instituições parecem não buscar ativamente esse tipo de recursos, em particular os ofertados pela Academia de Ciências da Finlândia. ${ }^{9}$ A despeito disso, o êxito na obtenção de recursos para pesquisa competitiva tem sido considerado um fator importante para ampliar o prestígio das politécnicas na Finlândia.

Conforme observado em outros estudos (por exemplo, Clark, 1997; Clark, 1998, p.141; Lyytinen et al. 2010; Slaughter; Leslie, 1997, p.175-176; Ylijoki et al. no prelo), esse trabalho também mostra que as várias áreas de conhecimento que formam uma instituição de ensino superior diferem entre si na maior ou menor proximidade em que se encontram do ambiente externo e na maior ou menor facilidade que têm para desenvolver uma postura empreendedora. Embora as politécnicas estudadas estejam empenhadas em encorajar todas as suas áreas de especialização a criar ligações diretas com o ambiente externo, é possível verificar que as diversas áreas se encontram em diferentes fases de desenvolvimento de uma cultura empreendedora. De uma maneira geral, as áreas técnicas têm tradição em contratos com parceiros externos e na produção de pesquisas aplicadas custeadas com recursos de fora. Por outro lado, as áreas relacionadas com atendimento de saúde ${ }^{10} \mathrm{e}$ assistência social encontram muito mais dificuldades para encontrar clientes dispostos a pagar por seus serviços. Ainda assim, a situação experimentou uma melhora expressiva também nessas áreas. Na experiência das Politécnicas A e C, por

${ }^{9} \mathrm{Na}$ experiência finlandesa, a Academia de Ciências é o principal órgão responsável pelo financiamento de pesquisas acadếmicas, desempenhando um papel similar àquele que no Brasil é de responsabilidade do CNPq. O acesso a esses recursos se dá principalmente através de programas e chamadas temáticas altamente competitivas (Nota da Tradução).

${ }^{10}$ No original: health care: essa expressão diz respeito a um conjunto de profissões ligadas à saúde, encarregadas do atendimento às necessidades cotidianas. Entre eles, estão, por exemplo, enfermeiros, técnicos em obstetrícia, técnico em geriatria, técnico em puericultura, etc.. 
exemplo, as escolas ligadas a essas áreas foram mencionadas como as que buscam ativamente alternativas para alcançar parceiros interessados em seus serviços. Nessas mesmas instituições, as escolas de recursos naturais também estão envolvidas em parcerias externas relevantes, particularmente com empresas agrícolas locais. Esses resultados foram possíveis principalmente através do acesso aos recursos da União Europeia.

Os resultados dapesquisamostram tambémque o sucesso no desenvolvimento do empreendedorismo e a reforma requerem um comprometimento deliberado e de longo prazo, além de atitude firme por parte de todo o corpo de funcionários e docentes da instituição.

\section{CONCLUSÃO}

Os resultados deste estudo mostram que as politécnicas finlandesas se capacitaram para um papel ativo no desenvolvimento regional de diversas maneiras que refletem a intensificação do empreendedorismo no interior dessas instituições. Entretanto, a aplicação do modelo de ação empreendedora para a realidade dessas instituições deve levar em conta o fato de que a história dessas organizações, como instituições multidisciplinares de ensino superior, ainda é muito recente. As politécnicas estão operando em bases permanentes apenas desde 2000, e só em 2003 elas tiveram seu papel no desenvolvimento regional oficialmente confirmado. Portanto, a história do engajamento regional dessas instituições ainda é nova e elas ainda estão à busca do formato mais adequado.

Em segundo lugar, mesmo que os elementos da mudança organizacional da universidade empreendedora, tais como descritos por Clark, de fato, ilustrem os desafios que as politécnicas finlandesas estão enfrentando, e mesmo considerando que essas instituições tenham recebido um mandato para desempenhar um papel mais atuante no desenvolvimento local, algumas restrições ainda se aplicam para o emprego desse modelo no caso das politécnicas. Essa situação é compreensí- vel, já que os conceitos propostos por Clark foram desenvolvidos para serem usados em universidades. A missão, as tarefas e a própria história das politécnicas são diferentes. Mesmo considerando que as políticas voltadas para esse setor e sua governança interna tenham aproximado as politécnicas do setor universitário, as politécnicas ainda assim se ressentem da ausência de uma tradição da autoridade acadêmica e da base científica que é comum nas universidades.

Em terceiro lugar, em comparação com outros países, especialmente a Grã-Bretanha e os Estados Unidos, as politécnicas finlandesas e outras instituições de ensino superior do país sempre tiveram, e ainda têm, uma forte missão pública, no sentido de oferecer serviços que criem benefícios à sociedade como um todo. Ademais, os recursos que custeiam as instituições de ensino superior da Finlândia são basicamente públicos. Nesse contexto, o surgimento de atitudes mais empreendedoras nas politécnicas responde prioritariamente às demandas colocadas pela política nacional de ensino superior. Portanto, o desafio que se coloca para essas instituições é o de encontrar caminhos de ação empreendedora que respondam, simultaneamente, às necessidades de cada região e também sejam apropriados à cultura e à sociedade do país como um todo.

(Recebido para publicação em 05 de junho de 2011) (Aceito em 15 de agosto de 2011)

\section{REFERÊNCIAS}

AUVINEN, P. Ammatillisen käytännön toistajasta monipuoliseksi aluekehittäjäksi? Ammattikorkeakouluuudistus ja opettajan työn muutos vuosina 1992-2010 [From repeating professional practise to versatile regional development? Polytechnic reform and polytechnic teachers'changing tasks 1992-2010]. Joensuun yliopiston kasvatustieteellisiä julkaisuja n.100. Joensuu: Joensuun yliopistopaino, 2004.

BIRNBAUM, R. How colleges work. The cybernetics of academic organization and leadership. San Francisco: Jossey-Bass Publishers, 1991.

CASTELLS, M. The information age. Economy, society and culture: the rise of the network society. Oxford: Blackwell Publishers, 2000. v.1. 
CLARK, B. The higher education system. Academic organization in cross-national perspective. Berkley: University of California Press, 1983.

Small worlds, different worlds: the uniqueness and troubles of american acdemic professions. Daedalus, Cambridge, v.126, n.4, p.21-42, 1997.

Creating entrepreneurial universities: organizational pathways of transformation. Surrey: Oxford: Pergamon Press, 1998.

ETZKOWITZ, H.; KLOFSTEN, M. The innovating region: toward a theory of knowledge-based regional development. R\&D Management, [S.1.], Willey, v.35, n.3, p.243-255, 2005

; LEYDESDORFF, L. Universities and the global knowledge economy: a triple helix of university-industrygovernment relations. London: Pinter, 1997.

; SCHULER JNR, E.; GULBRANDSEN, M. The evolution of the Entrepreneurial University. In: JACOB M.; HELLSTRÖM, T. (Ed.) The future of knowledge production in the academy. Buckingham: SRHE, 2000. p.40-60.

et al., The future of the university and the university of the future: evolution of ivory tower to entrepreneurial paradigm. Research Policy, [S.l.], Elsevier, v.29, n.2, p.313-330, 2000.

GIBBONS, M. et al. The new production of knowledge. The dynamics of science and research in contemporary societies. London: SAGE, 1994.

GOVERNMENT BILL 319/1994. Hallituksen esitys Eduskunnalle laiksi ammattikorkea-koulu-opinnoista ja eräiksi siihen liittyviksi laeiksi HE 319/1994. FINLEXtietokanta. Disponível em: www.finlex.fi/fi/.

GOVERNMENT BILL 206/2002. Hallituksen esitys Eduskunnalle ammattikorkeakoululaiksi ja laiks ammatillisesta opettajankoulutuksesta HE 206/2002. FINLEX-tietokanta . Disponível em: www.finlex.fi/fi/.

HAKALA, J. et al. Yliopisto - tieteen kehdosta projektimyllyksi? Yliopistollisen tutkimuksen muutos 1990luvulla [University - From a Birthplace of Science to Mill luvulla [University - From a Birthplace of Science to Mill
of Projects? The Change of University Research in the 1990’s]. Helsinki: Gaudeamus, 2003.

HÖLTTÄ, S. Towards the self-regulative university. Joensuun yliopiston yhteiskuntatieteellisiä julkaisuja n.23. Joensuu: Joensuun yliopisto, 1995.

JAATINEN, P. Synenergian siemenet ja torajyvät. Tutkimus monialaisen ammattikorkeakoulun organisaatiokulttuurista [Synenergy - a study of the organisational culture in a multidisciplinary polytechnic in Finland]. Turun yliopiston julkaisuja, Sarja C, Osa 148. Turku: Turun yliopisto, 1999

JACOB, M. et al H. Entrepreneurial transformations in the Swedish University system: the case of Chalmers University of Technology. Research Policy, [S.l.], Elsevier, v.32, n.6, p.1555-1568. 2003

KAUTONEN, M. et al. From the national industrial heartland towards a node in the global knowledge economy: the case of Tampere. In: SCHIENSTOCK, G. (Ed.) Embracing the knowledge economy: the dynamic transformation of the finnish innovation system. Cheltenham: Edward Elgar, 2004. p.169-195.

KOHTAMÄKI, V.. Financial autonomy of professional higher education institutions: the finnish AMKs in an international context. Tampere: Tampere University Press, 2004.

KRISTENSEN, B. The entrepreneurial university as a learning university. Higher Education in Europe, [S.l.], v.24, n.1, p.35-46, 1999.
LYYTINEN, A. Finnish polytechnics in the regional innovation system - towards new ways of action. Tampere: Tampere University Press, 2011. Disponível em: http:// acta.uta.fi/pdf/978-951-44-8408-7.pdf.

- MARTTILA L. Tutkimus- ja kehitystoiminta ammattikorkeakoulun ja sen toimintaympäristön välisenä vuorovaikutuksena [Research and development as the interaction between polytechnic and its environment]. TEOKSESSA AHMANIEMI, R. PANHELAINEN, M. (Ed.) Jyväskylän ammattikorkeakoulu tulevaisuuden tekijänä. Jyväskylä: Jyväskylän ammattikorkeakoulu, 2009. p.27-38.

YLIJOKI, O-H.; KAUKONEN, E.

Rakenteet muuttuvat - muuttuuko tutkimus? The structures change, does the research change? In: JULKAISUSSA AITTOLA, H. MARTTILA, L. (Ed.) Yliopistojen rakenteellinen kehittäminen, akateemiset yhteisöt ja muutos: RAKE-yhteishankkeen (2008-2009) oppuraportti. Opetusministeriön julkaisuja 2010, p.5. Helsinki, 2010. p.23-49.

MAASSEN, P. Editorial. European Journal of Education, [S.l.], v.35, n.4, p.377-383, 2000.

MARGINSON, S.; CONSIDINE, M.; The enterprise university: power, governance and reinvention in Australia. Cambridge: Cambridge University Press, 2000.

MARTTILA, L. et al. Yritysten ja ammattikorkeakoulujen T\&K-yhteistyö. [R\&D collaboration of companies and polytechnics]. Työelämän tutkimuskeskuksen työraportteja 69/2004. Tampere: Tampereen Yliopisto, 2004

MIETTINEN, R.; TUUNAINEN, J. Johdanto. Introduction. In: $\quad$ KNUUTTILA, T; MATTILA, E. (Ed.). Tieteestä tuottee $k s i$ ? Yliopistotutkimus muutosten ristipaineessa. [From Science to Product? University research in pressures of change]. Helsinki: Yliopistopaino, 2006. p.13-27.

et al. (Ed.) Tieteestä tuotteeksi? Yliopistotutkimus muutosten ristipaineessa. [From Science to Product? University research in pressures of change]. Helsinki: Yliopistopaino, 2006

NATIONAL BOARD OF EDUCATION Tietoja ammatillista koulutusta antavien oppilaitosten ja ammattikorkeakoulujen muutoksista vuosina 1990-2003 [Information about the changes of vocational educational institutions and polytechnics in 1990-2003]. Moniste 10/2003. Helsinki: Edita, 2003.

NIEMINEN, M.. Academic Research in Change. Transformation of Finnish University Policies and University Research during the 1990s. Helsinki: Finnish Society of Sciences and Letters. 2005

NOWOTNY, H.; SCOTT, P.; GIBBONS, M. Re-thinking science. Knowledge and the public age of uncertainty. Cambridge: Polity Press, 2002.

OECD. The response of higher education institutions to regional needs. Paris: OECD, 1999.

POLYTECHNICS ACT 351/2003. Ammattikorkeakoululaki 9.5.2003/351. FINLEX-tietokanta Disponível em: www.finlex.fi/fi/.

RAIVOLA, R. et al. Producing competencies for learning economy.. Helsinki: Hakkkapaino. 2001 (Sitra repports series,9)

RIUKULEHTO, S. Tietoa, tasoa ja tekoja. Seinäjoen ammattikorkeakoulun ensimmäiset kymmenen vuotta [Knowledge, high standard and actions. The first ten years of Seinäjoki Polytechnic]. Seinäjoen ammattikorkeakoulun julkaisusarja B. Raportteja ja selvityksiä 32. Jyväskylä: Gummerus, 2007.

SALMINEN, H. Suomalainen ammattikorkeakouluuudistus ja eurooppalainen integration: finnish 
polytechnic reform and European integration. Tutkimus,[S.1.], v.14, n.4, p.311-322, 1995.

Suomalaisen ammattikorkeakoulun syntyyn vaikuttaneita tekijöitä: contributing factors in the emergence of the finnish polytechnic. Kasvatus, Uusimaa,Fi, v.28, n.4, p.312-325, 1997.

SCHIENSTOCK, G. Transformation and learning: a new perspective on national innovation systems. In:

KUUSI, O. (Ed.) Transformation towards a learning economy. The challenge for the finnish innovation system. Helsinki: Sitra 213, 1999. p.9-56.

et al. Escaping path-dependency: the case of Tampere, Finland. In: COOKE, P.; HEIDENREICH, M. BRACZYK, H.J. (Ed.) Regional innovation systems: the role of governance in a globalised world. London Routledge, 2004. p.127-153.

SLAUGHTER, S.; LESLIE, L. Politics, policies and the entrepreneurial university. Baltimore: John Hopkins University Press, 1997

SPORN, B. Adaptive university structures: an analysis of adaptation to socioeconomic environments of US and European universities. London: Jessica Kinsley Publishers, 1999.
SUOSARA, E. Laajenemisen portaat ja vaiheet vuonna 2000 [The steps and stages of Polytechnic's extension] In: TEOKSESSA PANHELAINEN, M. (Ed.) Kokeilua, kehitystyötä, tuloksia. Jyväskylän ammattikorkeakoulun alkuvaiheen tarina. Jyväskylän ammattikorkeakoulun julkaisuja 81. Jyväskylä: Jyväskylän ammattikorkeakoulu, 2007. p.126-143

THOMPSON, J. Organizations in action. Social science bases of adminsitrative theory. New Brunswick: Transaction Publishers, 2003.

TUlKKI, P.; LYYTINEN, A. Ammattikorkeakoulu innovaatiojärjestelmässä. Osa 1: Alueelliset innovaatioverkostot. [Polytechnic in innovation system. Part 1: Regional innovation networks] Väliraportti. Tampereen yliopiston työelämän tutkimuskeskuksen työraportteja 65/2001. Tampere: Tampereen Yliopisto, 2001.

WILLIAMS, G. An honest living or dumbing down? In: WILLIAMS, G. (Ed.) The enterprising university: reform, excellence and equity. Ballmoor: SRHE, 2003. p.3-19.

YLIJOKI, O-H et al. Entangled in academic capitalism? A case study on changing ideals and practices of university research. Higher Education, v.45, n.2, p.307-335, 2003. 


\section{THE ANSWER OF THE FINNISH POLYTECHNIC SCHOOL TO THE CHALLENGES O OF INOVATION AND REGIONAL DEVELOPMENT POLICIES}

\author{
Anu Lyytinen \\ Seppo Hölttä
}

This paper presents an analysis of the recent development of a part of the higher education in Finland. Its objective is to analyse how Finnish polytechnic school reacted to the new requirements to become responsive to regional needs and how they build up the necessary abilities to this regional engagement. The central theoretical framework are the institutional changing elements described by Burton Clark (1998) on his analysis about entrepreneurial universities. In particular the article focus on the channels and interfaces that those institutions have established with other players in the region.

KEY WORDS: Finland, higher education, regional development, polytechnic school, academic entrepreneurship.

\section{LA RÉPONSE DES ÉCOLES POLITECHNIQUES FINLANDAISES AUX DÉFIS DES POLITIQUES D'INNOVATION ET DE DÉVELOPPEMENT RÉGIONAL}

\author{
Anu Lyytinen \\ Seppo Hölttä
}

L'objectif de l'analyse du développement récent d'une partie de l'enseignement supérieur en Finlande, présenté dans ce travail, est de voir comment les écoles polytechniques finlandaises ont réagi aux nouvelles exigences afin de répondre aux besoins régionaux d'une part, et comment elles ont construit les compétences exigées par cet engagement régional d'autre part. Les éléments de changement institutionnel décrits par Burton Clark (1998) dans son analyse des universités entreprenariales constituent la base théorique essentielle de cette recherche. Larticle se concentre tout particulièrement sur les réseaux et les interfaces que ces institutions ont établi avec les autres acteurs régionaux.

MOTS-CLÉs: Finlande, enseignement supérieur, développement régional, écoles politechniques, entreprenariat académique.

Anu Lyytinen - Doutora e pesquisadora do Grupo Pesquisa sobre Ensino Superior da Universidade de Tampere, Finlândia (HEG). Suas pesquisa estão centradas na análise das relações que se estabelecem entre as instituições de ensino superior e seu entorno institucional, mudanças organizacionais internas a essas instituições e o estudo de sistemas regionais de inovação. Realizou vários projetos de pesquisa que têm por objeto as politécnicas e universidades finlandesas. O título de sua tese de doutorado é "Finnish Polytechnics in the Regional Innovation System: Towards New Ways of Action", publicada pela Editora da Universidade de Tampere.

Seppo Hölttä - Professor Titular da Universidade de Tampere, Finlândia, na área de Administração e Finanças de Instituições de Ensino Superior. Diretor do Grupo de Pesquisa em Ensino Superior da Universidade de Tampere. Esse Grupo é parte da Rede FINHERT (Rede Finlandesa de Pesquisa em Ensino Superior) e afiliado à Rede Europeia HEDDA (Associação para o desenvolvimento do Ensino Superior). As atividades de pesquisa do Prof. Hölttä convergem para a análise de processos associados ao desenvolvimento de sistemas nacionais de ensino superior e para o estudo das mudanças institucionais produzidas por esses processos. Suas análises sobre esse tema são alimentadas por suas extensas pesquisas e atividades de consultoria realizadas no âmbito da união europeia e em vários países na África e no leste europeu. No presente, está desenvolvendo estudos comparados sobre as mudanças ocorridas no âmbito das universidades finlandesas e chinesas, em resposta às novas demandas colocadas pelas políticas de inovação adotadas pelos dois países. 
